\title{
An approach to monitor the fraction of elemental carbon in the ultrafine aerosol
}

\author{
Harry ten Brink ${ }^{\mathrm{a}, *}$, Gerard Hoek ${ }^{\mathrm{b}}$, Andrey Khlystov ${ }^{\mathrm{c}}$ \\ ${ }^{a}$ Energy Research Centre of the Netherlands (ECN), PO Box 1, Westduinweg 3, 1755 Petten, The Netherlands \\ ${ }^{\mathrm{b}}$ Institute for Risk Assessment Sciences (IRAS), Environmental and Occupational Health Division, University of Utrecht, \\ Utrecht, The Netherlands \\ ${ }^{\mathrm{c}}$ Department of Civil and Environmental Engineering, Duke University, Durham, NC, USA
}

Received 4 March 2005; received in revised form 24 June 2005; accepted 13 July 2005

\begin{abstract}
Attempts were made to measure the fraction of elemental carbon (EC) in ultrafine aerosol by modifying an Ambient Carbonaceous Particulate Monitor (ACPM, R\&P 5400). The main modification consisted in placing a quartz filter in one of the sampling lines of this dual-channel instrument. With the filter all aerosol and EC contained in it is collected, while in the other line of the instrument the standard impactor samples only particles larger than $0.14 \mu \mathrm{m}$. The fraction of EC in particles smaller than $0.14 \mu \mathrm{m}$ is derived from the difference in concentration as measured via the two sampling lines.

Measurements with the modified instrument were made at a suburban site in Amsterdam, The Netherlands. An apparent adsorption artefact, which could not be eliminated by the use of denuders, precluded meaningful evaluation of the data for total carbon. Blanks in the measurements of EC were negligible and the EC data were hence further evaluated. We found that the concentration of EC obtained via the channel with the impactor was systematically lower than that in the filter-line. The average ratio of the concentrations was close to 0.6 , which indicates that approximately $40 \%$ of the EC was in particles smaller than $0.14 \mu \mathrm{m}$. Alternative explanations for the difference in the concentration in the two sampling lines could be excluded, such as a difference in the extent of oxidation. This should be a function of loading, which is not the case. Another reason for the difference could be that less material is collected by the impactor due to rebound, but such bounce of aerosol is very unlikely in The Netherlands due to co-deposition of abundant deliquesced and thus viscous ammonium compounds. The conclusion is that a further modification to assess the true fraction of ultrafine EC, by installing an impactor with cut-off diameter at $0.1 \mu \mathrm{m}$, would be worth pursuing.
\end{abstract}

(C) 2005 Elsevier Ltd. All rights reserved.

Keywords: Soot; Elemental carbon; Ultrafines; Organic carbon

\footnotetext{
*Corresponding author. Tel.: + 31224564148 ; fax: + 31224568488 .

E-mail address: tenbrink@ecn.nl (H. ten Brink).
}

\section{Introduction}

There is an indication that particles with a diameter smaller than $0.1 \mu \mathrm{m}$, the ultrafine (UF) primary particles, affect human health (Peters et al., 1997). Ultrafine particles are generated by diesel traffic and this type of transport appears to be correlated with health effects in 
children (Hoek et al., 2002). As a marker for fresh diesel emissions, black/elemental carbon (EC) is used, but it is likely that UF carbon is a better marker. The reason is that the fraction of black/EC in the UF particles is much larger inside cities than at regional sites (e.g., Berner et al., 1996; Hitzenberger and Tohno, 2001). However, there are not sufficient data to test the hypothesis that carbon in the UF fraction is a better marker for fresh diesel exhaust.

We report here a modification of an existing instrument, the Ambient Carbonaceous Particulate Monitor (ACPM, R\&P 5400), to monitor the fraction of EC in UF aerosol. These efforts were made in the late 1990s and the present reporting may seem somewhat outdated. The reason for the late action is the doubt on the validity of the data on EC generated by an ACPM. However, in a recently published study on an intercomparison of methods to measure carbon in Europe, it was found that the average value for EC obtained with the ACPM was within the range of those of the other participants. Furthermore, the day-to-day correlation with the other data, which stemmed from standard 24-h filter sampling and off-line analysis, was very good (ten Brink et al., 2004). The good performance of the ACPM prompted the present (re)analysis of the older EC data.

\section{Experimental}

\subsection{ACPM and modification}

ACPM (Rupprecht \& Pataschnick, type 5400) is a dual-channel instrument that consecutively samples aerosol in one of the two lines. Sampling occurs with impactors that have a cut-off diameter of $0.14 \mu \mathrm{m}$. While collection occurs in one channel, aerosol is analysed in the second, identical, line. The analysis consists in combustion of the carbon via a two-step procedure. In the first step the more easily combustible organic carbon is oxidised and measured as carbon dioxide. EC is defined as the carbon that remains after the first combustion step. The temperature of the first oxidation can be varied, but its default setting is at $340^{\circ} \mathrm{C}$, according to the original approach of Cachier et al. (1989) for a two-step oxidative procedure to discriminate carbon into EC and OC. In the second oxidation step, at a temperature of $750^{\circ} \mathrm{C}, \mathrm{EC}$ is determined. A more detailed description of the instrument and its longterm performance as a monitor can be found in Holler et al. (2002).

We made use of the dual-channel feature of the ACPM for measurement of the EC in the UF fraction, via the following modification. In one of the sampling lines the impactor was replaced by a quartz fibre filter. Unlike the impactor, this filter collects aerosols of all sizes. The ultra-fine fraction of EC can then be determined from the difference in concentration measured in the filter and impactor lines.

We checked the performance of this modification. The instrument blank was determined by sampling particlefree ambient air. The random variations in the EC blank of the line with filter had a standard deviation (SD) of $0.04 \mu \mathrm{g} \mathrm{m}^{-3}$ for a 24 -h aggregated value, which translates to a LOD (three times the SD value) for EC in the line with a filter of $0.12 \mu \mathrm{g} \mathrm{m}^{-3}$, which is not statistically different from that in the line with an impactor of $0.11 \mu \mathrm{g} \mathrm{m}^{-3}$.

There may be a question on the validity of EC data obtained with the ACPM in view of the current debate around the uncertainties in determination of the actual value of EC (e.g., Chow et al., 2004; Schmid et al., 2001). We do not pretend that the values obtained with the modified ACPM are the correct ones. However, we use the difference in concentration in the two channels to derive the fraction, which can be highly significant as long as this difference is large compared to the LOD.

A difference method is only meaningful when the analysis of samples in the two channels is highly comparable. We checked this comparability, prior to the modification, by measuring the carbon content of ambient aerosol at our laboratory site that is remote from direct sources. As a further check we used a second ACPM of which the sampling was desynchronised with that of the design ACPM. It was found that over a period of a month the correlation in the concentrations obtained via the two channels of the design ACPM was close to unity, but also the correlation of the concentrations obtained with the second instrument was high $\left(0.98 R^{2}\right)$ (Even et al., 1998).

Attempts were made to measure the UF fraction of OC in a way similar to that for UF-EC. Organic carbon (OC) is defined as the carbon oxidised in the first step. In fact, quite some time also at the field testing site was devoted to tests to obtain artefact-free measurement of the OC component. The reason is that $\mathrm{OC}$ is the major carbon component. We had hoped that the use of a denuder, made after a design by Eatough et al. (1993), would lower the blank to values that would permit assessment of OC. However, large artefacts in the filter line were observed, even in the impactor line. This precluded evaluation of the fraction of OC in the UFs and hence also assessment of the fraction of total carbon.

\subsection{Field testing}

The modified ACPM was tested within the framework of the larger ULTRA study on the health effects of PM (de Hartog et al., 2003). The measurements were made in a south-eastern suburb of Amsterdam (The Netherlands). The monitor was inside a brick shelter on the roof of 
a two-storey elderly home. This home is located at a distance of approximately $1 \mathrm{~km}$ from major thoroughfares. The inlet line for the ACPM was as short as possible to prevent losses of UF particles. A full description of measuring site and meteorological conditions can be found in report ECN-R-00-01 (available on the web as www.ecn.nl/docs/library/report/2000/r00001.pdf).

Measurements were performed from the end of December 1998 until the beginning of March 1999. The standard sampling duration per line of the ACPM was $1 \mathrm{~h}$; only at the onset of the measurements a $3 \mathrm{~h}$ cycle was applied. The number of days with data is limited, because of periodic malfunctioning of the monitor combined with a low frequency of servicing (limited to once or twice a week). As a matter of fact we experienced the same complications as mentioned by Holler et al. (2002) operating the instrument at a seemingly quite similar suburban setting. The most severe problems encountered were leaking valves and failure of the lamps used for heating. As discussed above, we also spent substantial time on attempts to eliminate artefacts in the sampling/measurement of OC.

The blanks for EC were periodically checked, for a period of a day, with aerosol-free ambient air, with and without a denuder. The aerosol-free air was produced by placing a high-efficiency filter in the sampling line. The blank values and variations in these values were very similar to those mentioned above for the testing at the laboratory and there was, hence, no indications of a sampling artefact for EC in any of the two lines of the instrument.

\section{Results and discussion}

Data (on EC) were obtained during two periods in the campaign, of which the last, a 3-week run in February, is the most relevant because of the hourly cycling between filter and impactor line. The concentrations of EC stemming from the two channels are shown in Fig. 1. It can be seen that there is a clear difference in concentration in the two channels, with concentrations in the impactor line being systematically lower. To further illustrate this, the average concentration per hour over the whole of the measuring period is displayed (Fig. 2). Overall, the EC concentration obtained in the channel with the filter was 1.23 versus $0.67 \mu \mathrm{g} \mathrm{m}^{-3}$ in the line with the impactor. The actual value of these data may be questionable, but of importance is the difference in concentration. The estimated combined uncertainty in this difference, on the basis of the LOD mentioned above, is less than $4 \%$, meaning that the difference is highly significant.

More illustrative for the systematically lower values in the impactor line is the scatter plot of the data in the two lines provided in Fig. 3, where the values aggregated to daily concentrations are shown. The average ratio of the concentrations in impactor and filter line, represented by the broken line, is 0.6 . This indicates that, by difference, on average $40 \%$ of EC is too small to be collected by the impactor and thus is "ultrafine" EC. A similar result was found for the measuring period in December in which the measuring cycle was $3 \mathrm{~h}$ per channel.

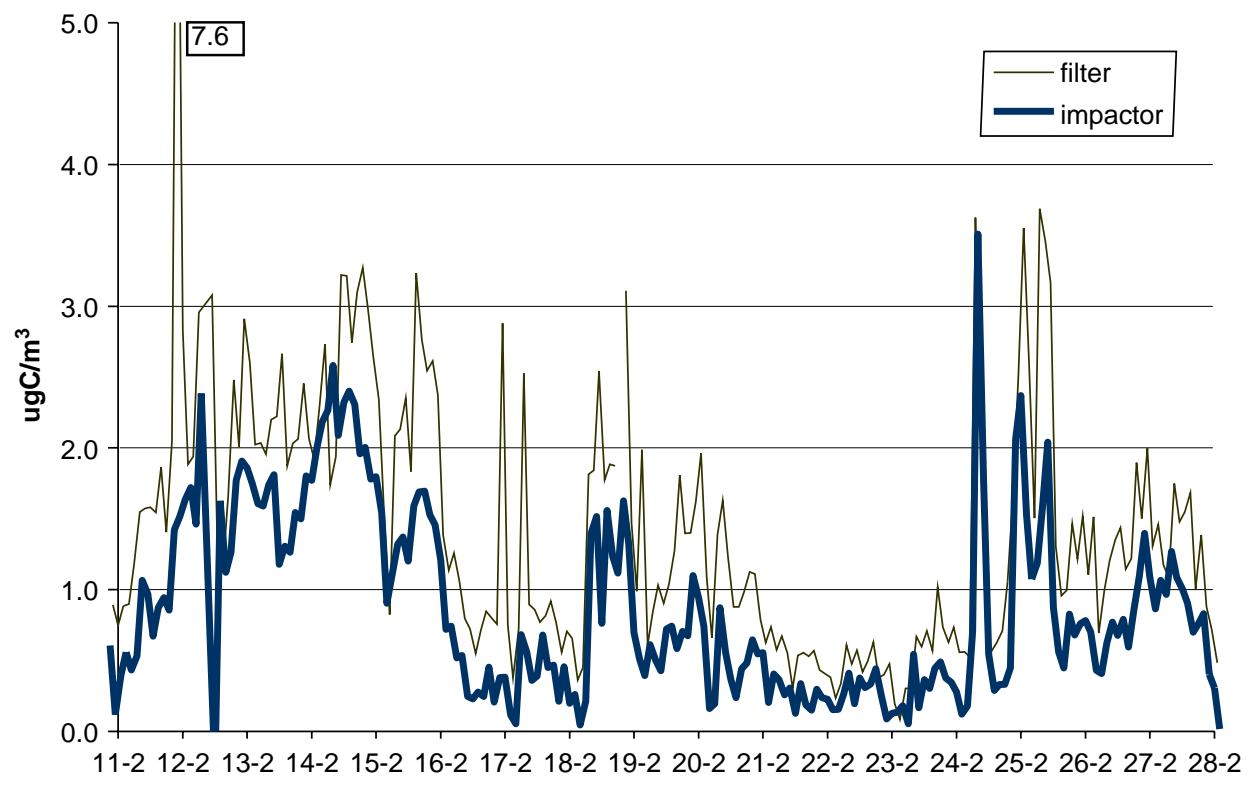

Fig. 1. Hourly concentration of EC as consecutively determined via impactor and filter line in the indicated period at a suburban site in Amsterdam, NL. 


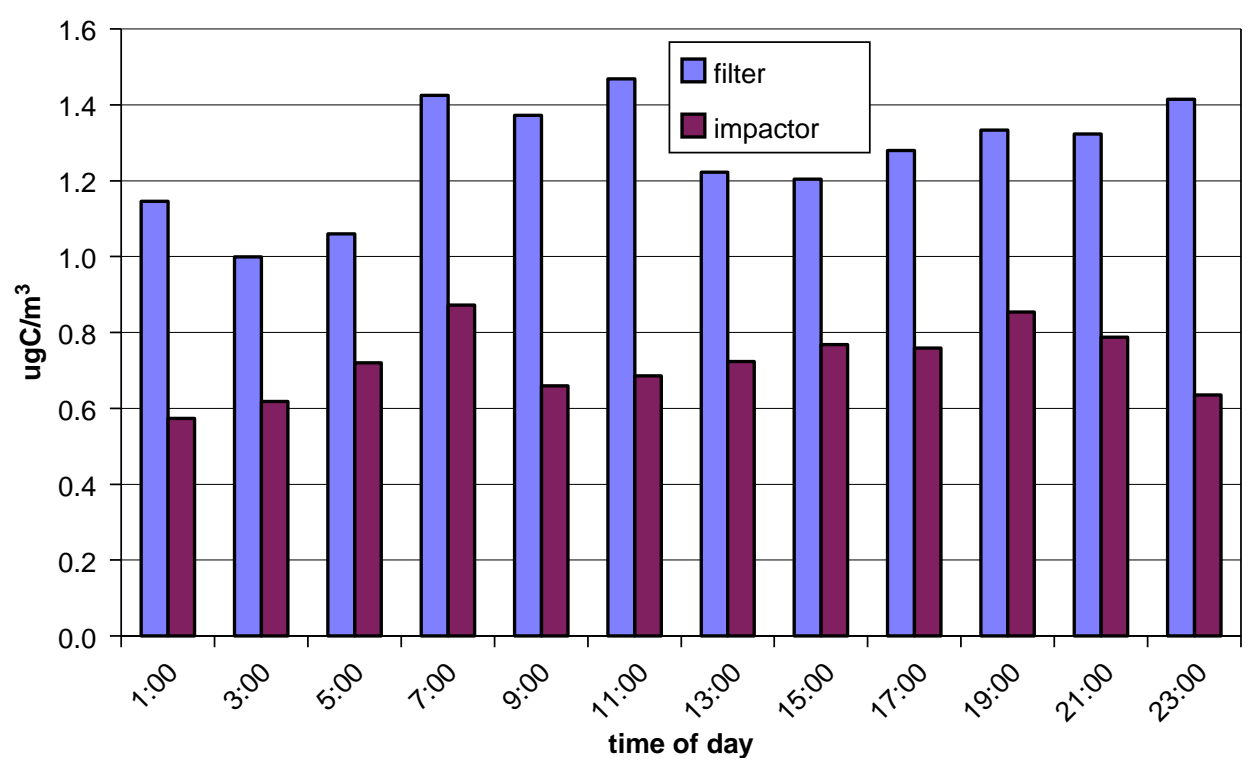

Fig. 2. Average hourly concentration of EC as determined in the impactor and filter channel of an ACPM in the period indicated in Fig. 1.

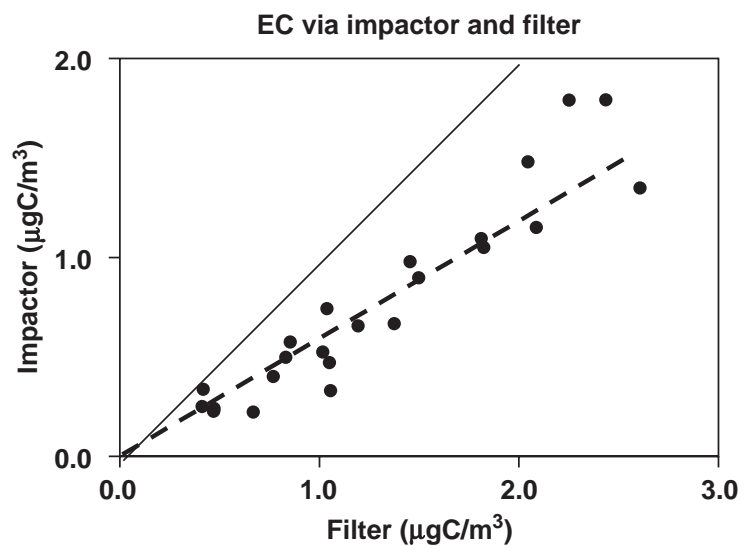

Fig. 3. Comparison of the daily concentrations of EC as determined via impactor line and filter line. The broken line represents a concentration ratio of 0.6 , corresponding to the average ratio. The vertical distances from the individual data to the thin solid (1:1) line are a measure for the fraction of ultrafine EC and the daily variation in this value.

There could be alternative explanations for the difference in EC between the two sampling lines. These, however, can be excluded as discussed below.

(1). There could have been a systematically higher ambient EC concentration in the hours when sampling occurred via the filter line, especially during rush hours. However, the data do not show a maximum at that time, see Fig. 1. To further check for temporal bias we used data for black carbon obtained with an aethalometer at a similar suburban site near the city of Utrecht in the same period. There are indeed indications for a rush hour peak in $\mathrm{BC}$ in the period 8:00-9:00 AM. However, this is the time that in our experiment the ACPM is sampling via the impactor line, but even then the values are less than those in the filter line in the hour preceding and following this period. There are two instances of large differences in concentration in consecutive hours in impactor and filter line, see Fig. 1. It is not certain whether this is a question of outliers. Anyhow, these values do not significantly affect the average difference.

(2). An alternative explanation of the difference in the signals in the two channels could be a difference in the extent of oxidation of the collected carbonaceous material. This should be a function of loading and, as seen in Fig. 2, the difference in the two lines is independent of the concentration.

(3). Another reason of the difference could be that the impactor samples less EC because of recoil (bounceoff) of these, solid particles, in the impactor. This is the reason that in a nitrate monitor, which is very similar to the ACPM, the aerosol is humidified to make the aerosol more adherent (Stolzenburg and Hering, 2000). Bounce of particles is very unlikely in The Netherlands, because the impaction surface will be covered with wet sticky aerosol particles, in the form of viscous hygroscopic ammonium salts that co-deposit with the EC particles (ten Brink et al., 2001). The deposit is viscous as long as the relative humidity exceeds or is near the deliquescence 
humidity of the mixed salt, which is close to $55 \%$ RH (Dougle et al., 1998). Such a meteorological situation was indeed the case in the test-period with its minimum $\mathrm{RH}$ of $62 \%$.

After clarifying that the difference in EC concentration in the two lines is due to the collection of UF-EC in the filter line, we may now analyse this difference. This difference is graphically the vertical distance of a point to the 1:1 line in Fig. 3. It can be deduced from the figure that there is quite a day-to-day variation in the fraction of UF-EC for similar values of total EC. A longer data-set is required to see under which conditions the fraction of UF-EC, representing fresh emissions, is highest and whether this is correlated with health effects. It should be noted that, formally, UF aerosol are particles smaller than $0.1 \mu \mathrm{m}$ in diameter. The cut-off diameter of the impactor in the ACPM is $0.14 \mu \mathrm{m}$. Thus, in the configuration we have used, not UF, but a slightly larger aerosol fraction was measured. It would be worthwhile to investigate whether the use of an impactor with cut-off at $0.1 \mu \mathrm{m}$, which has a higher pressure drop, is feasible.

\section{Conclusions}

We modified an Ambient Carbon Particulate Monitor and made the first measurements of the fraction of EC in particles smaller than $0.14 \mu \mathrm{m}$. In this field test, in suburban Amsterdam, on average $40 \%$ of the EC was in UF particles (particles smaller than $0.14 \mu \mathrm{m}$ ). A large adsorption artefact in the filter line prevented meaningful interpretation of the data for organic carbon and hence those for "total" carbon. The conclusion of this study is that further modification to assess the true fraction of UF-EC, by installing an impactor with a cutoff diameter at $0.1 \mu \mathrm{m}$, is worth pursuing.

\section{Acknowledgements}

We thank Arja Even for performing the tests and IRAS staff team for logistic assistance. We are grateful to Edith van Putten (National Institute of Public Health and the Environment of The Netherlands, RIVM, Bilthoven) for her ACPM and aethalometer data. Parts of this research were presented at the European Aerosol Conferences of 1998 and 2000 and included in the proceedings (Even et al., 1998, 2000).

\section{References}

Berner, A., Sidla, S., Galambos, Z., Kruisz, C., Hitzenberger, R., 1996. Modal character of atmospheric black carbon size distributions. Journal of Geophysical Research 101 (D14), 19,559-19,565.
Cachier, H., Bremond, M.P., Buat-Ménard, P., 1989. Determination of atmospheric soot carbon with a simple thermal method. Tellus 41B, 379-390.

Chow, J.C., Watson, J.G., Chen, L.-W.A., Arnott, W.P., Moosmüller, H., 2004. Equivalence of elemental carbon measured by thermal/optical reflectance and transmittance methods with different temperature protocols. Environmental Science and Technology 38, 4414-4422.

de Hartog, J.J., Hoek, G., Peters, A., Timonen, K.L., Ibald-Mulli, A., Brunekreef, B., Heinrich, J., Tiittanen, P., van Wijnen, J.H., Kreyling, W., Kulmala, M., Pekkanen, J., 2003. Effects of fine and ultrafine particles on cardiorespiratory symptoms in elderly subjects with coronary heart disease: the ULTRA study. American Journal of Epidemiology 157, 613-623.

Dougle, P.G., Veefkind, J.P., ten Brink, H.M., 1998. Crystallisation of mixtures of ammonium nitrate, ammonium sulfate and soot. Journal of Aerosol Science 29, 375-386.

Eatough, D.J., Wadsworth, A., Eatough, D.A., Crawford, J.W., Hansen, L.E., Lewis, E., 1993. A multiple-system, multi-channel diffusion denuder sampler for the determination of fine-particulate organic material in the atmosphere. Atmospheric Environment A 27, 1213-1219.

Even, A., Khlystov, A., ten Brink, H.M., 1998. Performance of two ambient carbon particulate monitors in background air. Journal of Aerosol Science 29, S873-S874.

Even, A., Khlystov, A., Kos, G.P.A., ten Brink, H.M., Hoek, G., Oldenwening, M., Hartog, J., 2000. Improvement of BC measurements with the ambient particulate monitor RP5400. Journal of Aerosol Science 31, S897-S898.

Hitzenberger, R., Tohno, S., 2001. Comparison of black carbon (BC) aerosols in two urban areas - concentrations and size distributions. Atmospheric Environment 35, 2153-2167.

Hoek, G., Brunekreef, B., Goldbohm, S., Fischer, P., van den Brandt, P.A., 2002. Association between mortality and indicators of traffic-related air pollution in the Netherlands: a cohort study. Lancet 360, 1203-1209.

Holler, R., Tohno, S., Kasahara, M., Hitzenberger, R., 2002. Long-term characterization of carbonaceous aerosol in Uji, Japan. Atmospheric Environment 36, 1267-1275.

Peters, A., Wichmann, H.E., Tuch, T., Heinrich, J., Heyder, J., 1997. American Journal of Respiratory and Critical Care Medicine 155, 1376-1383.

Schmid, H., Laskus, L., Abraham, H.J., Baltensperger, U., Lavansky, V., Bizjak, M., Burba, P., Cachier, H., Crow, D., Chow, J., Gnauk, T., Even, A., ten Brink, H.M., Giesen, K.-P., Hitzenberger, R., Hueglin, C., Maenhaut, W., Pio, C., Putaud, J.-P., Toom-Sauntry, D., Puxbaum, H., 2001. Results of the "carbon conference" international aerosol carbon round robin test stage 1. Atmospheric Environment 35, 2111-2121.

Stolzenburg, M.R., Hering, S.V., 2000. A new method for the automated measurement of atmospheric fine particle nitrate. Environmental Science and Technology 34, 907-914.

ten Brink, H.M., Khlystov, A., Kos, G., Tuch, T., Roth, C., Kreyling, W., 2001. A high-flow humidograph for testing the water uptake by ambient aerosol. Atmospheric Environment 34, 4291-4300.

ten Brink, H.M., Maenhaut, W., Hitzenberger, R., Gnauk, T., Spindler, G., Even, A., Chi, X., Bauer, H., Puxbaum, H., Putaud, J.-P., Tursic, J., Berner, A., 2004. Comparability of methods in use in Europe for measuring the carbon content of aerosol. Atmospheric Environment 38, 6507-6519. 